\title{
Aix-les-Bains - 18-20 rue Isaline
}

\section{Gilles Ackx}

\section{OpenEdition \\ Journals}

Édition électronique

URL : http://journals.openedition.org/adlfi/15577

ISSN : 2114-0502

Éditeur

Ministère de la culture

Référence électronique

Gilles Ackx, "Aix-les-Bains - 18-20 rue Isaline », ADLFI. Archéologie de la France - Informations [En ligne], Rhône-Alpes, mis en ligne le 01 septembre 2015, consulté le 01 mai 2019. URL : http://

journals.openedition.org/adlfi/15577

Ce document a été généré automatiquement le 1 mai 2019.

(c) Ministère de la Culture et de la Communication, CNRS 


\title{
Aix-les-Bains - 18-20 rue Isaline
}

\author{
Gilles Ackx
}

Code INSEE de la commune : 73008

Lien Atlas (MCC) :

http://atlas.patrimoines.culture.fr/atlas/trunk/index.php?

ap_theme=DOM_2.01.02\&ap_bbox=5.872;45.665;5.936;45.724

1 Peu d'intervention archéologiques ont eu lieu dans la ville d'Aix-les Bains. Elles remontent le plus souvent au XIX ${ }^{\mathrm{e}} \mathrm{s}$. et concernent son centre monumental thermal et son lieu de culte. Trois opérations récentes, menées en 1996 par A.-C. Rémy, B. Ode et D. Lalaï (1996), ont livré des vestiges d'habitat dans un rayon assez proche de l'ensemble thermal.

2 Le projet de construction d'un immeuble sur deux étages avec parking souterrain offre la possibilité sur une distance plus importante du centre antique de révéler la présence éventuelle de vestiges de l'Antiquité, et par la même occasion de vérifier l'extension de l'agglomération gallo-romaine.

3 L'ouverture de trois sondages sur le site de la rue Isaline a permis de mettre au jour une occupation des alentours du $\mathrm{III}^{\mathrm{e}} \mathrm{s}$. qui se manifeste par deux aménagements. Le premier est un sol formé en partie de galets centimétriques, créant ainsi un espace ouvert propre à toute activité humaine. Le second correspond à un épais empierrement mis en œuvre probablement pour assainir et rendre accessible une zone très humide à cause de remontées d'eau de la nappe phréatique.

4 Deux fondations de murs, non datées, construites en travers de la pente, ont également été mises en évidence. Il pourrait s'agir de murs de clôture.

5 L'opération de diagnostic de la rue Isaline a permis de mettre en évidence une occupation antique sous la forme d'aménagement de sol en vue d'exercer des activités humaines qui n'ont malheureusement pas pu être caractérisées. La structuration des vestiges est, semble-t-il, assez lâche, donc aucunement comparable à une organisation urbaine classique durant l'Antiquité. Le site de la rue Isaline pourrait s'inscrire dans un contexte périurbain, sous la forme d'une occupation dispersée de l'espace aménagé. La présence, 
en grand nombre, de matériaux de construction (tuiles à rebord) et de céramiques dans un niveau de colluvionnement du sondage $n^{\circ} 3$ laisse supposer qu'il y avait quelques constructions antiques dans le voisinage immédiat de cette zone.

INDEX

Index chronologique : Antiquité

Mots-clés : aménagement de sol, tuile, céramique

Keywords : Antiquity

operation Opération préventive de diagnostic (OPD), 2013 - n OA : 2211178

Index géographique : Rhône-Alpes, Savoie (73), Aix-les-Bains

\section{AUTEURS}

GILLES ACKX

Inrap 